\title{
APPLICATION OF ALTERNATIVE ENERGIES IN THE COTOPAXI PROVINCE, ECUADOR
}

\author{
Edwin Homero Moreano Martínez \\ Master in energy management. Electromechanical engineering career, \\ Technical University of Cotopaxi, Latacunga, Ecuador.
}

Edison Patricio Salazar Cueva

Master's degree in safety and prevention of occupational risks. Electromechanical Engineering Career, Technical University of Cotopaxi, Latacunga, Ecuador

Cristián Fabian Gallardo Molina

Master in energy management. Electromechanical Engineering Career, Technical University of Cotopaxi, Latacunga, Ecuador

Luis Rolando Cruz Panchi

Master in energy management. Electromechanical engineering career, Technical University of Cotopaxi, Latacunga, Ecuador

Carlos Alfredo Espinel Cepeda

Electromechanical Engineer. Magister in renewable energies. Electromechanical Engineering Career, Technical University of Cotopaxi, Latacunga, Ecuador

\begin{abstract}
The possibility to accessing to electricity consists in the usage of energies: Hydraulic, solar, wind, geothermal and biomass. These energies are capable of doing work; nowadays this energy is used for the operation of machines that are part of our everyday life and are useful for the economic development of our country and the wellness of its population. Although this should be considered a human right, unfortunately there are who in the so-called technological modernization lack this resource that is vital due to our country's geographic situation. Currently this reality is being eliminated with the appearance of new resources of electric power generation that are consubstantial with the environment, it is so in the last twenty years are being implemented technologies to obtain electrical energy from other sources that the planet has. The objective of this work is to provide electrical energy by applying wind and solar energy to the population that does not have this service from the analysis and tabulation of the data obtained from the wind speed and the solar radiation. We have also evaluated the behaviour of demand, implemented small power plants and finally the measurement of the main electrical variables. In conclusion it is evident that this type of systems is applicable and above all profitable; as long as the places are separated and far from the electrical distribution system.
\end{abstract}

Keywords - Renewable sources, Alternative energy, Electric generation, wind speed, solar radiation, engineering.

\section{INTRODUCTION}

The energy and the different forms of use by man have delineated the development of human society in each of its evolutionary stages. Over the years, humanity has perfected the use of electrical energy, going from the simplest methods to the most complex methods applied today; in order to satisfy their needs.

Today, $90 \%$ of the energy needs of the planet are met with the use of fossil fuels (oil, gas, coal). All of them are extinguishable, strongly polluting and used inefficiently. The importance of reducing the consumption of these primary sources has turned into an economic problem, a vital problem, which became one of the biggest accidents that have occurred in the development of humanity due to the environmental difficulties that were derived of its exploitation, we are giving solution to a rebirth of renewable energies (Zhanxin et al. 2018).

All the technology developed by man implies the use of different forms of energy, for this reason, it is supported to the electrical generation for each of its applications in all sectors of our country according to Jaafarian et al. (2018). Therefore, it is necessary to work for electricity generation in any environmental scenario without contributing to global warming. 


\section{International Journal of Engineering Applied Sciences and Technology, 2019 \\ Vol. 3, Issue 11, ISSN No. 2455-2143, Pages 47-52 \\ Published Online March 2019 in IJEAST (http://www.ijeast.com)}

In this sense, Alatorre et al. (2009), defines renewable energies as those whose source resides in phenomena of nature, processes or materials susceptible of being transformed into energy usable by mankind, and that regenerate naturally, for which they are available continuously. Renewable sources of energy will last for thousands of years. According to this definition, we can consider that solar and wind energy are continuous and inexhaustible energies because their supply comes from the phenomena of nature and that it is used in electricity generation for new opportunities in all rural sectors, since they can satisfy the same needs as the other types of energy (AL-Naely, Al-Khafaji and Khassaf, 2018). Energy is present in almost all aspects of existence and its availability is considered as something natural.

One of them is the solar energy obtained by capturing the light and the heat emitted by the sun. The solar radiation that reaches the earth can be exploited by means of the heat that it produces through the absorption of the radiation. According to the manifested it can be considered that the solar energy is a term that is used to refer to the techniques that are used Directly solar radiation. In this way, solar energy can be divided into two types: the photovoltaic solar that is responsible for directly transforming the radiation into electricity thanks to the photovoltaic effect and the solar thermal that uses the direct heating capacity of the sun according to Hernández and Santamarta, (2015).

For the implementation of our research we use photovoltaic solar energy since this type of energy allows us to supply electrical energy from solar cells designed to directly transform part of the solar energy. The solar cells are constituted by a semiconductor material, in which the electrons are sufficiently little bound to be taken away by the energy of the incident photons (Moro, 2010). In this way, they can circulate freely through the semiconductor, traveling the glass as if it were a positive charge. That is to say, the scheme is that of electrons crossing the solar cell and that of hollow spaces that are those that remain when the electron circulates. Once this has been achieved, the links must be prevented from re-establishing themselves through their recombination.

This type of energy has the advantage of being produced on the site that is required, thus avoiding additional costs for transportation and losses by the transmission lines. Similarly, according to Van (2008), states that wind energy originates from the movement of air masses, that is, wind. Like most renewable energy sources, it comes from the sun, since it is the differences in temperature between the different geographical areas of the earth that produce the circulation of air.

From the point of view of wind energy, the most important characteristic of wind is its variability, both from a geographical and temporal point of view. On a large scale, spatial variability describes the fact that in the world there are different climatic zones, some with greater availability of resources than others, determined mainly by their latitude.
To determine the wind power that can be provided by the wind that is given in Watts, we can calculate using equation (1).

$P e=\frac{1}{2}(r h o)($ Area $)\left(V v^{3}\right)$

Where, Pe is Wind power in Watts. Rho is Air density in $\mathrm{Kg} /$ $\mathrm{m}^{3}$. Area is Wind turbine front surface in $\mathrm{m}^{2} \cdot \mathrm{Vv}^{3}$ is Wind speed in $\mathrm{m} / \mathrm{s}$. Among the main advantages of small-scale wind farms in rural areas are: possibility of supplying electricity in isolated places and far from the electricity supply network, possibility of replacing or supplementing the energy obtained from it; the generation of electrical energy next to the points of consumption, accessibility for any type of user due to its simple installation, and generation of greater welfare and social equity in rural communities contributing to development due to the possibility of accessing a greater degree of technology (Nguyen, 2006).

The origin of this research is presented by noting the lack of electricity in sectors of the province of Cotopaxi due to its geographical location, specifically in aspects such as electricity generation through solar and wind energy, where possible demands of each sector to Nieto (2004).

With the proposal of this research is intended to contribute to electricity generation in sectors that do not have this service and as teaching material within a public institution such as the Technical University of Cotopaxi, allowing the saving of energy consumption of it, in addition encouraging the university community to apply alternative energies and contribute to environmental conservation.

This project integrates the theoretical information that describes in a general way, the theoretical position adopted to develop the research, the methodology of work, the analysis and results of the data obtained from the wind speed and solar radiation in the University, and the implementation of the solar and wind infrastructure for power generation.

\section{METODOLOGY}

For the application of this project it is required to know the place of the implementation and the capacity of electrical generation, obtained by the equipment through the existing natural resources of the sector, the designation of the place was applied by the need to energize the equipment and electrical appliances (luminaries, information processors, among others), which are used for the application of the Germoplasma project, which is located in the Choasilli sector, La Esperanza parish, Pujili canton, and as teaching material to encourage students to use alternative energies in the Technical University of Cotopaxi, Eloy Alfaro parish, Simón Rodríguez avenue, El Ejido / San Felipe neighborhood, Latacunga Canton, Cotopaxi province, Ecuador. Table 1 shows the application of the GPS that is a device that allows to obtain the latitude and altitude of each one of the selected sectors, the following geographical locations. 


\section{International Journal of Engineering Applied Sciences and Technology, 2019 \\ Vol. 3, Issue 11, ISSN No. 2455-2143, Pages 47-52 \\ Published Online March 2019 in IJEAST (http://www.ijeast.com)}

Table 1. Geographical locations of Choasilli and Technical University of Cotopaxi

\begin{tabular}{|c|c|c|c|}
\hline \multicolumn{2}{|c|}{ Choasilli } & \multicolumn{2}{c|}{ Technical University of Cotopaxi } \\
\hline SO & $0^{\circ} 58.218^{\circ}$ & SO & $0^{\circ} 123.423^{\circ}$ \\
\hline WO & $79^{\circ} 05.073^{\circ}$ & WO & $29^{\circ} 36.321^{\prime}$ \\
\hline Height & $1919 \mathrm{msnm}$. & Height & $2890 \mathrm{msnm}$. \\
\hline Humidity & $78 \%$ & Humidity & $14 \%$ \\
\hline $\begin{array}{c}\text { Maximum } \\
\text { temperature }\end{array}$ & $38^{\circ} \mathrm{C}$ & $\begin{array}{c}\text { Maximum } \\
\text { temperature }\end{array}$ & $22,7^{\circ} \mathrm{C}$ \\
\hline $\begin{array}{c}\text { Minimum } \\
\text { temperature }\end{array}$ & $22^{\circ} \mathrm{C}$ & $\begin{array}{c}\text { Minimum } \\
\text { temperature }\end{array}$ & $3^{\circ} \mathrm{C}$ \\
\hline
\end{tabular}

Once the sectors were determined, the following procedure was carried out; for the Technical University of Cotopaxi, the measurement instruments were implemented to perform an energy diagnosis, allowing us to obtain the necessary data and thus determine the natural resource (solar and wind), existing to obtain the electric power; once determined the natural resources, by means of the weather station WatchDog WD 2700 allowed us to obtain the direction and the speed of wind, the temperature, the relative humidity of the air, the pluviosidad, standing out for the implementation of the electrical generation the direction of the wind, the maximum and minimum speed according to Schallenberg, Piernavieja and Hernández, (2008).

In addition, by applying the solar radiation meter, we were able to measure the solar intensity Ptot (in $\mathrm{W} / \mathrm{m}^{2}$ ), equipment that was located at a height of nine meters above the top of Block B of the parent building, which were obtained during a year; however, for the Choasilli sector, due to its geographical location, the existing resource for electricity generation was determined to be solar energy, in such a way that the radiation meter was implemented to obtain it, fundamental aspects to contribute to the application of renewable energies, avoiding the emission of gases for global warming (Technical Committee AEN/CTN, 2007).

After the compilation of data, the behaviour of the solar radiation and that of the consumed charge was reviewed, same that a respective analysis was made with the photovoltaic panel of 250 and $130 \mathrm{Wp}$ with outputs of $48 \mathrm{VDC}$, which means that for each level of radiation, there is a behaviour in the maximum power that the module can deliver, this allows us to propose implementation alternatives for the generation of $2 \mathrm{~kW}$ in the main building and $500 \mathrm{~W}$ in the Choasilli sector according to Manuals on renewable energy, (2002) and Jara, (2006).

\section{Experimental technique}

The investigation of the parameters for the electric generation was made on a residential scale. The installation is equipped with equipment and software that allow higher quality in data recording, control and manipulation of variables.

\section{Data from the meteorological station}

Once the measurements were obtained that were programmed in the system in a lapse of 15 minutes during a year from the month of September 2014 to the month of August 2015, forming a series of planned measurements to be later downloaded to the computer using the Spec Ware software 9 professional, making it easier to explore the information and graph the wind behaviour curve as shown in figure 1, which was essential to be able to analyse and discuss the maximum, minimum and average speed and the predominant direction, since this will help determine the behaviour of the same, for the implementation of the electric generator.

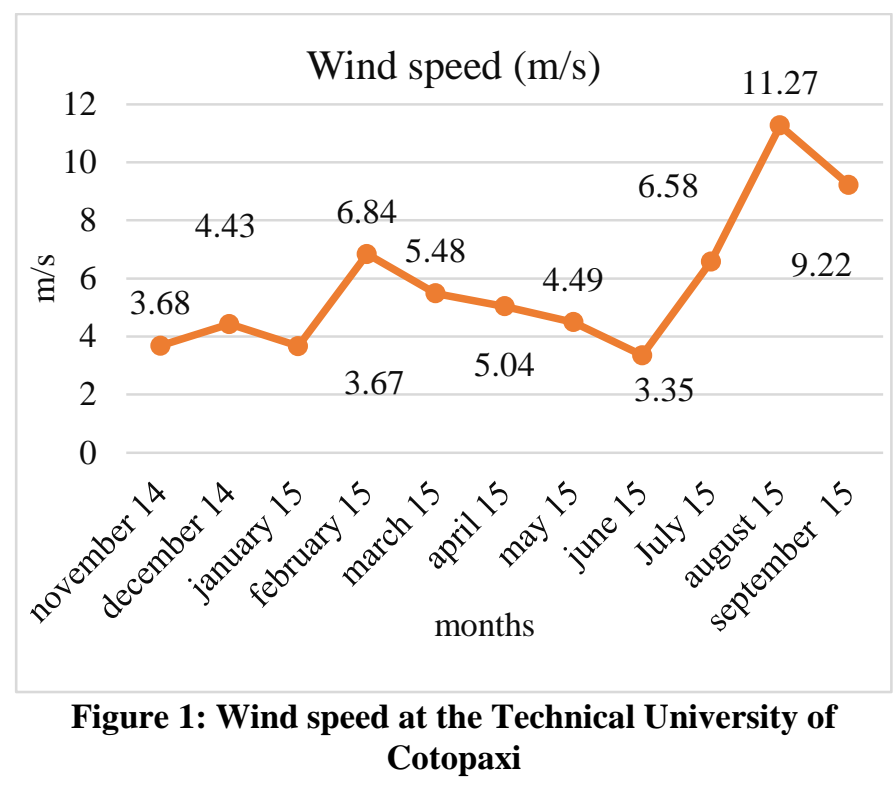

Figure 1 shows the data obtained from the month of November 2014 until September 15, 2015 in which it can be seen that there is a maximum speed in the month of August of $11.27 \mathrm{~m} / \mathrm{s}$, a minimum speed in the month of May of $3.35 \mathrm{~m} / \mathrm{s}$ and an average speed of $5.81 \mathrm{~m} / \mathrm{s}$. It was also possible to analyse in the data obtained that there are gusts of wind (turbulence) that reaches speeds of up to $19.28 \mathrm{~m} / \mathrm{s}$, shown in figure 2 . 


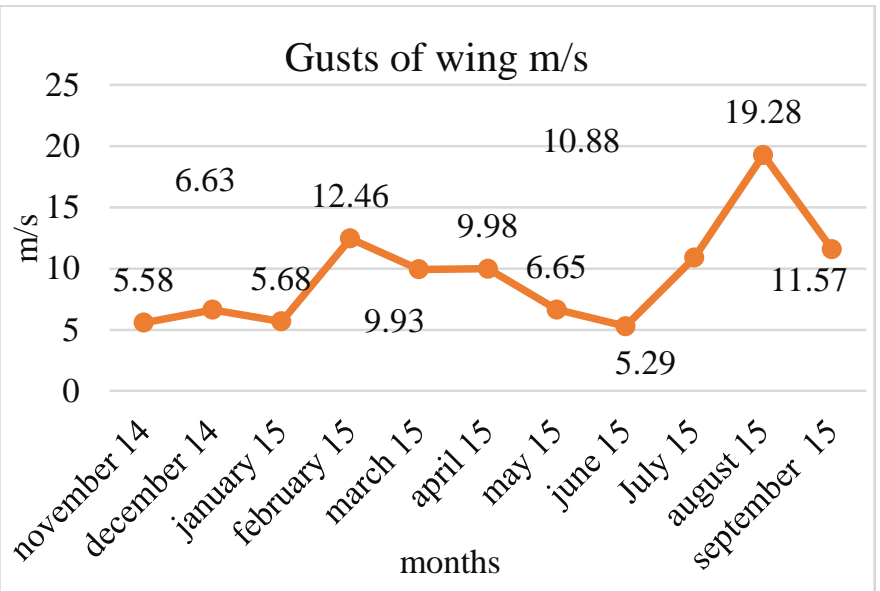

Figure 2: Gusts of wind from the Technical University of Cotopaxi

It is very important to describe the variation of wind speed since information is needed for the implementation of the wind turbine and to minimize its costs. A model used to describe the variation of wind at a given location is the Weibull distribution as shown in Figure 3, which are for the 7:00, 13:00 and 19:00 hours.

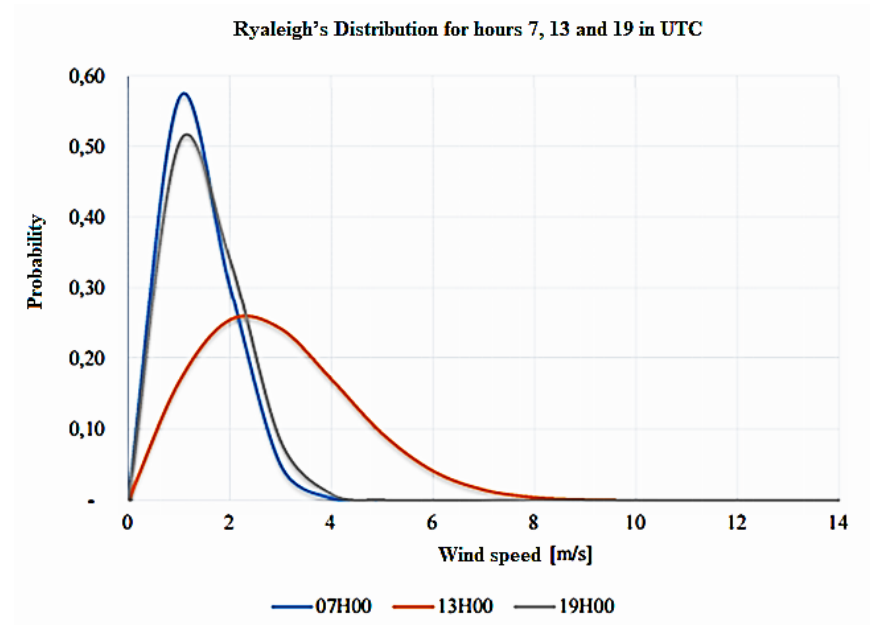

Figure 3: Weibull distribution

Figure 3 shows a probability distribution. The area under the curve is always exactly 1 , since the probability that the wind blows at any of the speeds, including zero, must be $100 \%$. The Weibull distribution indicates that the probability that the wind blows at low speeds is higher than in the case that it blows at high speeds; If you measure the wind speeds over a year, you can see that in the majority of the area the strong gales are rare, while the cool and moderate winds are quite common, the statistical distribution of wind speeds vary from one place to another. to another of the terrestrial globe depending on its geographic formation and local climatic conditions.

\section{Solar mac data}

In order to obtain radiation data, the equipment was installed in the university's main building, carrying out a series of planned and monitored measurements recording the date and time of the measurement.

\section{Data in the technical university of cotopaxi block b}

As can be seen in figure 4 , the maximum radiation value is $786,542 \mathrm{Wh} / \mathrm{m}^{2}$ in the month of March 2015 and the minimum value of $523,467 \mathrm{Wh} / \mathrm{m}^{2}$ in the month of February 2015, with an average value of $691.30 \mathrm{Wh} / \mathrm{m}^{2}$.

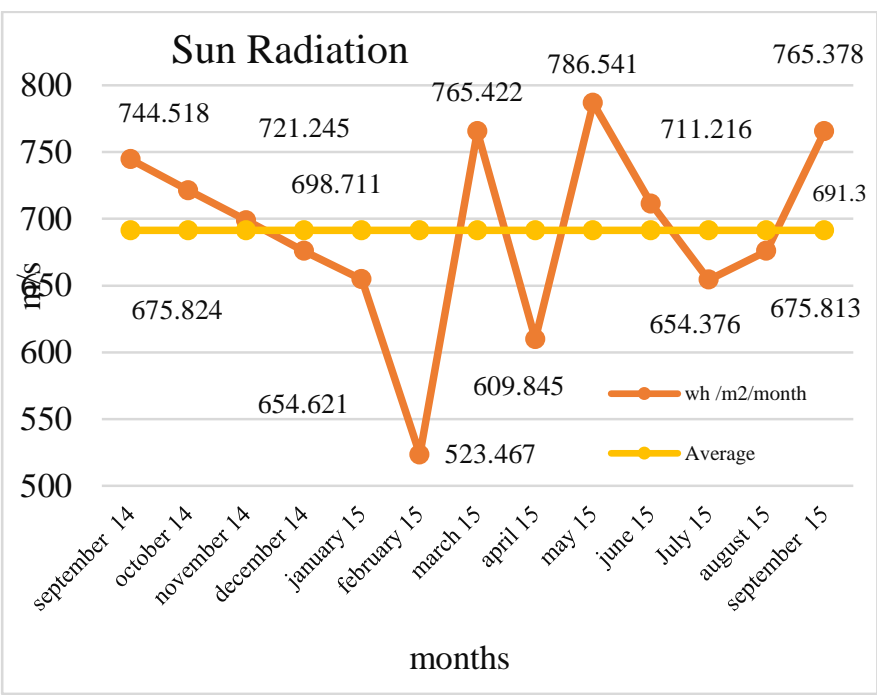

Figure 4: Sun radiation in "B" Building

\section{Data obtained in Choasilli}

By using the radiation meter for a day in the assigned sector we can determine the radiation levels as shown in figure 5 for the implementation of the photovoltaic power plant.

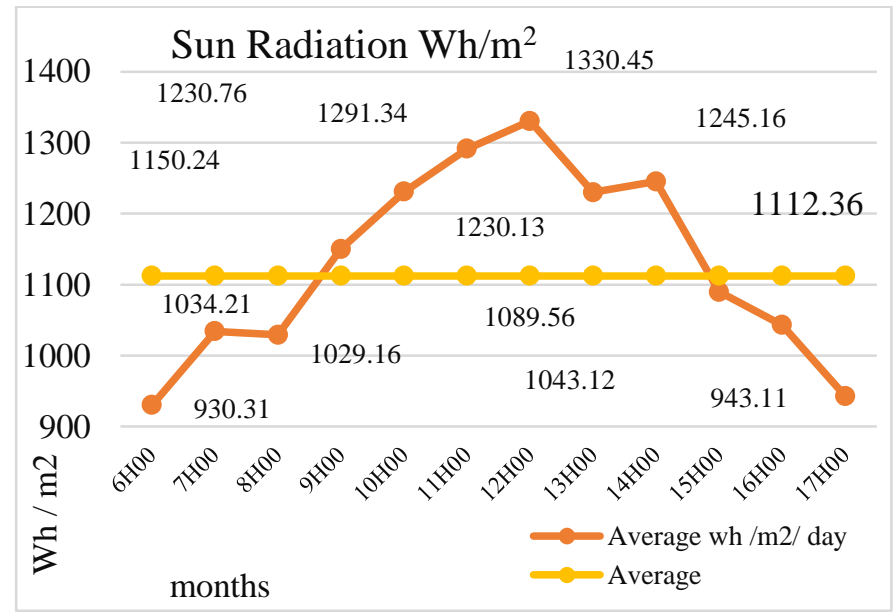

Figure 5: Daily sun radiation 


\section{International Journal of Engineering Applied Sciences and Technology, 2019 \\ Vol. 3, Issue 11, ISSN No. 2455-2143, Pages 47-52 \\ Published Online March 2019 in IJEAST (http://www.ijeast.com)}

As can be seen in Figure 5, the highest radiation value is $1330.45 \mathrm{Wh} / \mathrm{m}^{2}$ after 12.00 and the lowest is $930 \mathrm{Wh} / \mathrm{m}^{2}$ after 6:00 AM, thus allowing a generation of $500 \mathrm{~W}$.

What is determined in figures 4 and 5 is that in this period of time the solar radiation exceeds the standard values that are specified in the solar panels allowing a correct operation in the photovoltaic panels.

\section{RESULTS AND DISCUSSION}

\section{Implementation of a hybrid electric generator through the wind and solar system}

Once analysed the data of the direction and speed of the maximum, minimum and average wind, we proceed to the implementation of the wind generator since it seeks to guarantee the reliability required during the useful life of the equipment and produce the electricity at the lowest possible cost per kilowatt-hour $(\mathrm{kWh})$ of energy. Using wind resources efficiently, when selecting a correct location to install a wind turbine, it is not enough to study the wind maps or take wind measurements in the area. In addition to this we must take into account other factors that can greatly influence the future behaviour of the wind turbine.

Wind speeds are affected by friction with the earth's surface. In general, the more pronounced the rugosities of the terrain, the greater will be the slowing down experienced by the wind. Turbulence reduces the possibility of using wind energy effectively in a wind turbine. The turbulences cause greater breaks and wear in the wind turbine. The obstacles that the wind encounters such as buildings, trees, rock formations, etc. They can slow down the wind significantly and often create turbulence around them. So it is best to avoid large obstacles near wind turbines and in particular if they are located just in front (Jara, 2006).

Therefore, it is important to locate the wind turbines in the direction of the prevailing winds, with minimum obstacles and the lowest possible roughness in that direction taking into account hill and tunnel effects, for this reason it was placed nine meters above the "B" Building's terrace "B" of the matrix.

Applying equation 1 determines the power that can be provided by the wind at different speeds, considering an area swept by the blades $1.44 \mathrm{~m} 2$, which would be the area corresponding to a wind turbine with a horizontal axis with a rotor of $0.45 \mathrm{~m}$ and a height of $1.6 \mathrm{~m}$. In addition, the kinetic energy of a body in motion is proportional to its mass. Thus, the kinetic energy of the wind depends on the density of the air. At normal atmospheric pressure and at $15^{\circ} \mathrm{C}$, the air density is $1,255 \mathrm{~kg} / \mathrm{m}^{3}$ although this value decreases slightly with the increase in humidity and with the maximum, minimum and average speeds that we will have.

In reference to the sweeping area of the blades, this determines how much wind energy is capable of capturing the wind turbine. The larger the diameter of the blades, the greater the surface area and therefore the energy absorbed by the rotor is greater. But we must consider the vibration generated by the wind system with respect to wind speed.

In the same way, the solar radiation data were analysed and it was established that the appropriate angle of inclination is 15 degrees because the equator is at the latitude zero of the terrestrial globe. Prior to the acquisition of the wind infrastructure as solar needed to meet the established demand, the design of the plans for the assembly required in the Choosily sector and in the University was carried out, as shown in Figures 6 and 7 respectively. The same that allows us to comply with the technical characteristics of each of the equipment for its proper functioning.

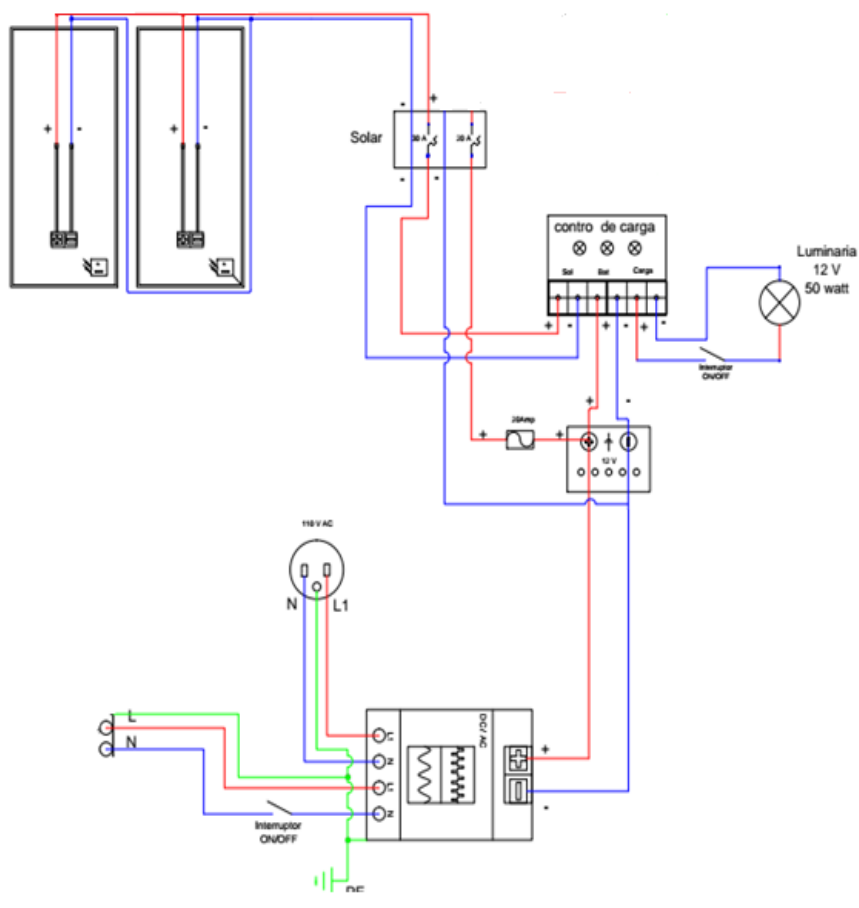

Figure 6. Choasili Diagram 


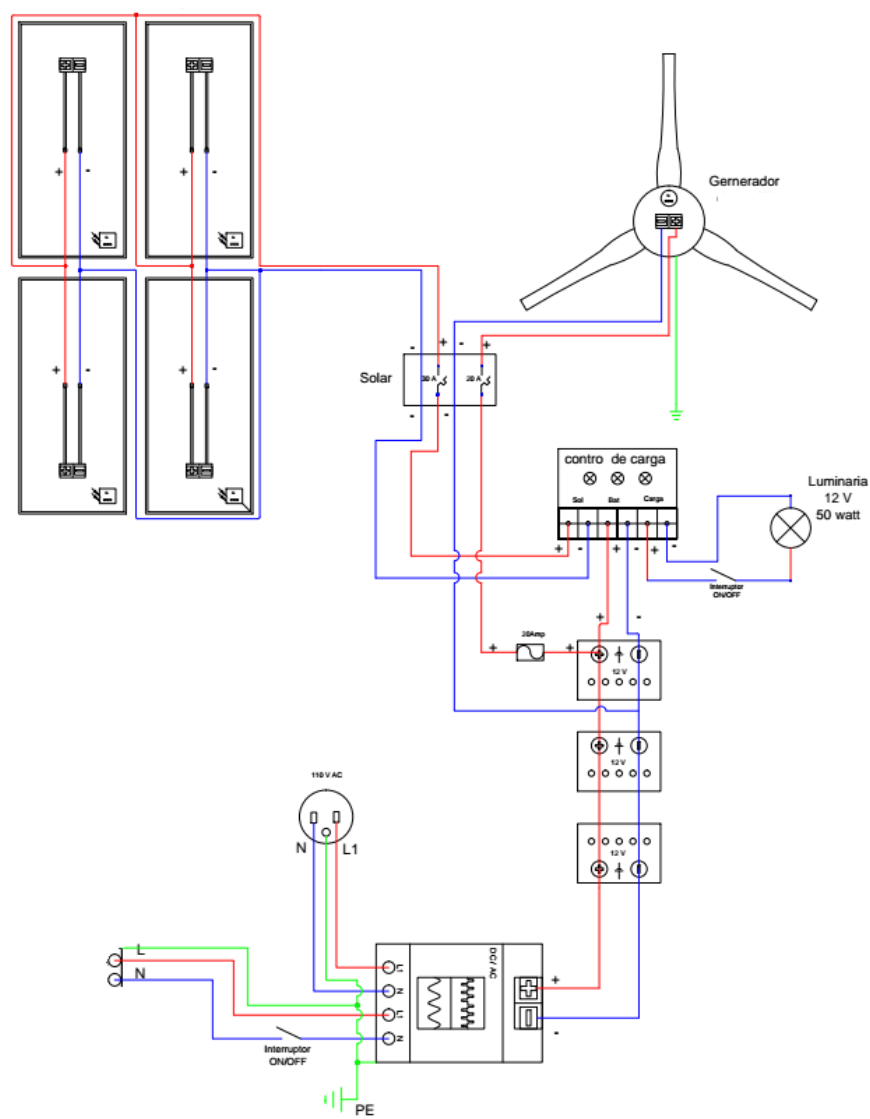

Figure 7. "B" building Diagram

By means of the application of the network analyzer, measurements were made of the following magnitudes: current, voltage, power, energy consumption, frequency and power factor, involved in the energy management of the generation.

\section{CONCLUSION}

The complete electric generation model has been implemented to cover some demand, consisting of photovoltaic modules and a small wind turbine, as well as the application of natural solar and wind resources. In addition to the implementation of this system is considerable in sectors where the power lines are not located by the geography of our country because the costs of electricity generation by this system are high, due to the high cost of equipment, in addition to existing the presence of turbulence up to $19.28 \mathrm{~m} / \mathrm{s}$ reduces the useful life of the wind turbine, at the same time causing vibration in the infrastructure in this way putting at risk the life of the human being.

One of the contributions of this work is that, based on previous works of electrical generation, detailed models of wind and solar energy obtained with wind and photovoltaic electric generators have been generated, and have been united in a single model, allowing to investigate the Hybrid system dynamics.

\section{REFERENCE}

[1] Alatorre Frenk C., Valle Pereña J., Eckermann A. and Barzalobre, V. (2009). Solar energy. México.

[2] AL-Naely, H., Al-Khafaji, Z., Khassaf, S. (2018). Effect of Opening Holes on the Hydraulic Performance for Crump Weir. International Journal of Engineering, 31(12), (pp. 2022-2027).

[3] Hernández-Gutiérrez, L.E., Santamarta, J.C. (2015). Geological Engineering in Volcanic Lands. Madrid: Illustrious Official College of Geologists.

[4] Jaafarian, M., Ebrahimi-Nejad R., S., Kazemain, M. (2018). Experimental Investigation of Energy Consumption and Performance of Reverse Osmosis Desalination using Design of Experiments Method. International Journal of Engineering, 31(1), (pp. 79-87).

[5] Jara Tirapegui, W. (2006). Introduction to NonConventional Renewable Energies. First Edition. ENDESA; Santiago de Chile.

[6] Manuals on renewable energy (2002). Solar Fotovoltaica/Biomass Users Network (BUN-CA). -1 ed. San José, C. Biomass Users Network (BUN-CA).

[7] Moro Vallina, M. (2010). Photovoltaic solar installations. types of photovoltaic cells. First edition. Editions paraninfo S.A; Madrid Spain.

[8] Nguyen, K. (2006). Alternatives to grid extension for rural electrifcation: Decentralized renewable energy technologies in Vietnam. Energy Policy, 35, (pp. 25792589).

[9] Nieto Rodríguez, J. (2004). Solar Energy. Vigo: Galicia Spain.

[10] Schallenberg J., Piernavieja, G. and Hernández C. (2008). Renewable energies and energy efficiency. First edition; Instituto Tecnológico de Canarias.

[11] Technical Committee AEN/CTN 216. (2007). Renewable Energy. Standard: Spain.

[12] Van De Wyngard, H. (2008). Renewable Energies. Spain.

[13] Zhanxin, Y., Fang, Z., Lixiong, X., Hongjun, L., Dapeng, X., Junnan, L., Yu, D., Yalei, L. (2018). Investigation on Equivalent Trans-utilization Mode and Benefit of Wind Energy. International Journal of Engineering, 31(10), (pp. 1708-1714). 